\title{
Progress of research on urban-rural transformation and rural development in China in the past decade and future prospects
}

\author{
LIU Yansui ${ }^{1,2}$, LONG Hualou ${ }^{1}$, CHEN Yufu ${ }^{1}$, WANG Jieyong ${ }^{1,2}$, LI Yurui ${ }^{1}$, \\ LI Yuheng ${ }^{1}$, YANG Yuanyuan ${ }^{1,2}$, ZHOU Yang ${ }^{1,2}$ \\ 1. Institute of Geographic Sciences and Natural Resources Research, CAS, Beijing 100101, China; \\ 2. Academy of Land and Urban-Rural Development, Beijing Normal University, Beijing 100875, China
}

\begin{abstract}
Urban-rural transformation and rural development are issues at the forefront of research on the topic of the urban-rural relationship in the field of geography, as well as important practical problems facing China's new urbanization and overall planning of urban and rural development. The Center for Regional Agricultural and Rural Development, part of the Institute of Geographic Sciences and Natural Resources Research under the Chinese Academy of Sciences, was established in 2005. The Center has laid solid foundations for integrating research in the areas of agricultural geography and rural development in China over the past decade. The paper aims to review the major achievements in rural geographical research in China during the past decade, analyze innovative developments in relevant theories and methods, and suggest prospects and countermeasures for promoting comprehensive studies of urban-rural transformation and rural geography. The research shows that innovative achievements have been made in rural geography studies of China in the past decade as major national policy development, outputs of result and decision making support; new breakthroughs have been achieved in such major research projects as geographical integrated theory, land remediation projects and technology demonstration projects, new urbanization and urban-rural integration; significant progress has been made in actively expanding the frontiers of rural geography and pushing forward theoretical innovations in land and resource projects; and, with China's development goals of building a moderately prosperous society in all respects and achieving modernization in mind, future innovative developments in agricultural and rural geography should aim to make research more strategic, systematic, scientific and security-oriented, with attention given to promoting systematic scientific research on international cooperation and global rural geography.
\end{abstract}

Keywords: urban-rural transformation; rural development; rural geographical projects; urbanization; China

Received: 2016-04-30 Accepted: 2016-05-10

Foundation: National Natural Science Foundation of China, No.41130748, No.41471143

Author: Liu Yansui (1965-), Professor, specialized in land use science and urban-rural development.

E-mail: liuys@igsnrr.ac.cn 


\section{Introduction}

The urban-rural relationship is the most basic economic and social relationship of human beings. As rapid industrialization and urbanization continue, urban-rural transformation and sustainable rural development become important issues at the forefront of geographical research on the urban-rural relationship. International rural geography studies during the past decade has focused on agricultural and food security, the quality of the living environment and land use issues. Agricultural and food security has laid the research foundations on agricultural and rural development. Lobell et al. (2008) believe that by the middle of this century the world's population will reach 9 billion, which will pose a serious threat to global food security. At the same time, climate change will have profound and sustained impact on global agricultural and food security through its effect on food production, food supply, food use and access to food (Schmidhuber and Tubiello, 2007; Brown and Funk, 2008). In recent years, improving the quality of the rural living environment and making urban and rural areas more equal have become a popular topic in international rural geography studies (Liu et al., 2013a). As the rapid socio-economic development and the rising problems such as reduced arable land and land degradation and contamination (Liu Yansui et al., 2014), the concepts of sustainable use, cleaning up and improving the ecology of land have received widespread attention from the academic sphere, accelerating research on developing regional land development, rebuilding empty villages, reclaiming waste land and managing the rural environment (Liu et al., 2015b).

Since joining the World Trade Organization in the 21 st century, China has been facing huge changes and challenges in terms of international trade competition and industrial restructuring (Liu, 2007). In 2003, the Third Plenary Session of the 16th Central Committee of the Communist Party of China (CPC) proposed the "five balances" (balancing urban and rural development, balancing development among regions, balancing economic and social development, balancing development of man and nature, and balancing domestic development and opening up to the outside world), which emphasized the need to balance urban and rural development and gradually change the dualistic urban-rural economic structure. In 2005, the Fifth Plenary Session of the 16th CPC Central Committee proposed the overall strategy of "building a new socialist countryside", with the emphasis on promoting urban-rural integration. The Chinese central government announced it would abolish a 2600-year-old agricultural tax, which became an important symbol of innovation in China's rural system. The rapid urbanization initiated 20 years ago by China's Ninth Five-Year Plan has induced the rural depopulation from 859 million in 1995 to 603 million in 2015, an average of 100 million migrates from rural areas to urban areas each decade. In 2005, the pattern of China's grain production was found to shift from "the south supplying the north, to the north supplying the south", as cultivated land use and food production changed dramatically in China (Wang and Liu, 2009).

The Chinese geographers have carried out systematic studies of agricultural and rural transformation and development. Most notable of these were studies on rural development and transformation (Liu, 2007; Long et al., 2011; Fang and Liu, 2014; Li et al., 2015b; Qiao et al., 2016), urban-rural transformation processes (Li Yuheng et al., 2014a; 2015a) and effects (Zhou et al., 2015), urban-rural equalization (Liu et al., 2013a; 2015b), migration of 
the rural population and rural hollowing (Long et al., 2009a; Chen et al., 2010; Chen et al., 2014; Liu Shaoquan et al., 2014; Wang et al., 2013), regional agriculture (Li et al., 2011; Liu, 2011), food security (Wang et al., 2009; Huang et al., 2012), valley economies (Zhang et al., 2009), poverty alleviation and development (Liu et al., 2016), rural land improvement (Liu, 2011; Yun and Yu, 2011; Wang et al., 2012), rural reconstruction (Chen et al., 2008; Long et al., 2012, 2016; Long, 2014), and building a new countryside (Liu, 2007; Long et al., 2010; Li Yurui et al., 2015).These studies called for more comprehensive, systematic and forward-looking research to promote Chinese agricultural geography and rural development as a distinct academic discipline.

The Center for Regional Agricultural and Rural Development (CRARD) at the Institute of Geographic Sciences and Natural Resources Research under the Chinese Academy of Sciences was established in 2005 in response to the national strategic needs and the need to develop rural development as a discipline, which facilitated the research on Chinese agricultural geography and rural development and transformation in the 21st century. In 2006, the Center was awarded a grant to undertake the National Natural Science Foundation of China's first major project in the field of rural geography, entitled "Research on New Countryside Development Models and Sustainable Paths in China's Eastern Coastal Areas." That same year, the Geographical Society of China set up a separate venue at its annual conference for the first time to host seminars on "modern agricultural and rural development", and reestablished its Scientific Committee on Agricultural Geography and Rural Development. During the past decade, the Center has laid solid foundation for integrating research on agricultural geography and rural development in China. The paper aims to review the major achievements made in urban-rural transformation and rural development research in China over the past decade, analyze innovative developments in relevant theories and methods, and suggest prospects and countermeasures for promoting comprehensive studies on urban-rural transformation and rural geography.

\section{Major research and projects in Chinese rural geography during the past decade}

\subsection{Comprehensive agricultural and rural geography}

In the area of agricultural geography, the CRARD team carried out a National Key Basic Research Project (973 Program) entitled "Impact of Northern Aridification on Land and Water Resources and Food Security and Adaptive Strategies (2006-2010)", which revealed the processes and mechanism of the impact of climate change on land and water allocation and food production in northern China, and analyzed scientific means and measures for future structural adjustments to local water supply and land use as well as food security guarantees in northern China under different scenarios.

In the area of urban-rural development, the CRARD team carried out a key project of the National Natural Science Foundation entitled "Research on New Countryside Development Models and Sustainable Paths in China's Eastern Coastal Areas" (2006-2010), which achieved remarkable progress in the theoretical system, multi-scale simulations and evaluations, and national strategic consultancy of the new countryside development. In 2011, the 
CRARD team was granted another key project, entitled "Resource and Environmental Effects of Urban-Rural Development and Transformation in China and Their Optimal Adjustments-A Case Study of the Bohai Rim" (2012-2016). The team also carried out an important study of the CAS Knowledge Innovation Project entitled "Rural Hollowing and Resource and Environmental Effects in the Course of Rapid Urbanization", which simulated and analyzed the processes of rural hollowing and the laws behind its life cycle, revealed the reasons and mechanisms behind rural hollowing, proposed a model and measures for remedying hollowed villages and promoted the practical experiences of Yucheng City in Shandong, Dancheng county in Henan and Yaozhou district in Shaanxi.

The National Natural Science Foundation's funding situation reflects the development of rural geography. Given the rapid development of rural geography, the National Natural Science Foundation Committee has added it to the human geography subject category. Three project applications were received for funding in this sub-discipline in 2008, and rapid increase of both project applications and acceptances afterwards, around 20 projects funded each year since 2012. Since 2008 a total of 88 projects have been funded with the support of more than RMB 30 million yuan. There has also been a continuous increase in projects managed by scholars of rural geography and approved by the Ministry of Science and Technology, Ministry of Land Resources, National Development and Reform Commission, and other relevant departments. Between 2014 and 2016, CRARD oversaw the completion of three national major projects, including projects on China's rural land system and targeted domestic poverty alleviation.

\subsection{Land improvement projects and technology demonstrations}

Research on land use strategies is an important basis for formulating overall land use plans and land improvement plans. In 2006, the CRARD carried out a project commissioned by the Ministry of Land Resources "National Land Use Strategy Research", which proposed a red line for arable land protection, a fan-shaped model for land strategies in China, and a sustainable land use strategy system for China (Liu, 2011). In 2011, the CRARD carried out the "Major Shaanxi Weihe River High-quality Farmland Construction Project" and a feasibility study and typical engineering design and investment estimation for a project entitled "Centrally Supported Major Project for Gully Reclamation and Land Improvement in Yan'an, Shaanxi" in 2012 (Liu, 2015). The former project aims to provide support for the development of 5 million $m u$ (333,500 ha) of high-quality farmland, while the latter involved jointly issuing documents and granting approval ([2013] no. 914) from the Ministry of Land Resources and Ministry of Finance to develop 506,000 $m u$ (33,750 ha) of farmland, with project investment of RMB 4.832 billion yuan.

The CAS Knowledge Innovation Project entitled "Research on Potential and Planning of Village Land Improvement" was the first study based on remote sensing images and household surveys, and it proposed a three-tier classification system, delimited hollowing village types, suggested potential improvements to hollow villages, put forward countermeasures to implement rural land improvement projects adopted by the State and received important comments from the central leadership (Liu et al., 2011b; Liu et al., 2013b). "Key Technological Research and Demonstrations on Comprehensive Improvement of Hollow Villages", which was part of the "12th Five-Year National Science and Technology Support Program" 
and overseen by CRARD, began in January 2014, with the focus on developing key technology for investigating, planning and improving hollowing villages, researching technical specifications for comprehensive improvement of hollowing villages and integrated demonstrations of key technologies for improving hollowing villages in different regions.

Funded by both the national and provincial projects targeting on the actual requirements of land improvement projects and modern agricultural project construction, the CRARD has established different types of land and resource project research and test bases: the modern agricultural engineering research demonstration base in the Mu Us Sandy Land in Yulin, Shaanxi, where it carries out land improvement and modern agricultural seed experiments and research; the channel land improvement and sustainable use demonstration base in the loess hills and gullies in Baota District of Yan'an, where it carries out integrated observational tests on channel improvement, slope stability and land sustainability; hollowing village improvement and technological integration demonstration base on an agricultural plain in Yucheng city, Shandong, where it carries out "three-in-one (land creation, soil formulation and soil improvement)" engineering and technology system tests; and the targeted poverty alleviation and county development research demonstration base in the mountainous region of Fuping, Hebei, where it carries out hillside ecological land improvement projects and demonstrations and research on nurturing distinctive industries. Based on the observations and experiments at its various bases, the CRARD promotes comprehensive research and practice in the engineering, scientific and technological aspects of agriculture, land and resources.

\subsection{New urbanization and urban-rural integration}

In the course of rapid industrialization and urbanization, "rural malaise" becomes increasingly serious (Liu, 2013; Bai et al., 2014), imposing new requests for in-depth and comprehensive studies on new type of urbanization and urban-rural integration. The CRARD team has helped to launch the CAS consultation projects "China Rural Urbanization Models and Paths" and "Rational Progress of Urbanization in China Under the Guidance of Overall Urban and Rural Planning", as well as the Chinese Academy of Engineering's consultation project "Planned Construction and Management of Villages and Towns", which provided a systematic discussion of the paths and models for traditional rural urbanization, the new urbanization model from the perspective of overall urban and rural development, and village and town construction. The CRARD also received a major project by the National Social Science Foundation entitled "The Impact of Urbanization on China's Agricultural and Rural Development and Countermeasures" (2016-2017). This project focuses on analysis of the basic urbanization theories as well as agricultural and rural development, spatio-temporal evolution and problem diagnosis of China's agricultural and rural development, the spatio-temporal pattern and overall effect of China's urbanization, mapping and measuring the impact of urbanization on agricultural and rural development, and models and countermeasures of the boost to agricultural and rural development from urbanization.

Given the forward-looking and leading nature of the research and decision-making consultation work in the areas of urbanization, rural development and land use, in 2014 the General Office of the CPC Central Committee entrusted the CRARD team a study entitled "Research on Rural Land System Reform in China" (2014), in which they proposed the ba- 
sic principles and objectives for rural land system reform, anticipated effects and risks, and promoted major policies of the reform. Research results from the study have been used in pilot projects on rural land system reform in China since last year. In 2015, the General Office of the State Council entrusted the CRARD team with the task of "carrying out a third-party assessment of the implementation of major policies and measures of the State Council on targeted poverty alleviation and reduction." Led by the Institute of Geographic Sciences and Natural Resources Research, CAS, a 75-person team of research experts were involved and studied the "island effect" and rural differentiation mechanisms of rural impoverishment (Liu et al., 2016; Li, 2016; Yang et al., 2016), and proposed a six-point assessment system and policy recommendations for targeted poverty alleviation that have been used in related poverty-alleviation and development documents issued by the CPC Central Committee.

\subsection{Rural geography frontiers and multidisciplinary integration}

In the course of rapid industrialization and urbanization, there have been constant changes in the roles and functions of agriculture and rural areas as well as their positions in society (Woods, 2005). The focus of agricultural geography studies has gradually shifted from theories and methods of agricultural zoning and the laws of regional differentiation in agriculture to regional agricultural functions (Liu and Lu, 2003; Liu et al., 2011a). While the Chinese rural geographers have been deepening their research on traditional agricultural geography, with economic and social transformation and development as the main thread, they have also continued to absorb new geographic features and new variables, and enriched and developed research from agricultural production systems to rural regional systems. They have promoted pioneering and systematic research, theoretical innovations and discussions on scientific paradigms in areas as new countryside development models (Liu, 2007), comprehensive improvement to hollowing villages (Liu et al., 2010; Long et al., 2012; Li Yurui et al., 2014), major rural land improvement projects (Liu, 2015), urban-rural development and transformation (Yang et al., 2015), urban-rural equalization (Liu et al., 2015a), rural assessments (Li Yurui et al., 2015; Long et al., 2009b) and rural policy evaluations (Long et al., 2010; Li et al., 2013a).

In response to scientific issues of rural development, national strategic requirements and local practical requirements, there have been efforts to promote a multidisciplinary system, involving land and resource engineering, new countryside development geography, rural geography engineering and urban-rural transformation geography, and interdisciplinary development. And in accordance with the reconstruction and coupling of factors, structures, functions and effects, these efforts have contributed to the organic integration of natural science, engineering, management and environmental science, and rehabilitated and developed integrated rural geography with Chinese characteristics (Liu and Yang, 2015). For example, in the course of industrialization and urbanization, problems of land resource development, use and management have become increasingly prominent, and the current accumulated knowledge, research directions and technical methods related to land resources will make it difficult to provide effective support to solve major practical problems. It is, therefore, imperative to strengthen research and practice in the area of land resources engineering (see Figure 1). In light of this, CRARD has pushed forward integrated multidisciplinary re- 
search. In the gully reclamation and land improvement projects in Yan'an, geographers provide services and support for the entire process of major national project planning and construction, from project proposals, feasibility studies, program planning and development, typical engineering design, project investment and budgets, and implementation, to national expert appraisals, on-site inspections, and project approval and construction. This results in practical exploration and advancement of interdisciplinary research and its application in the areas of national land improvement, which involves resources, land engineering and land management.

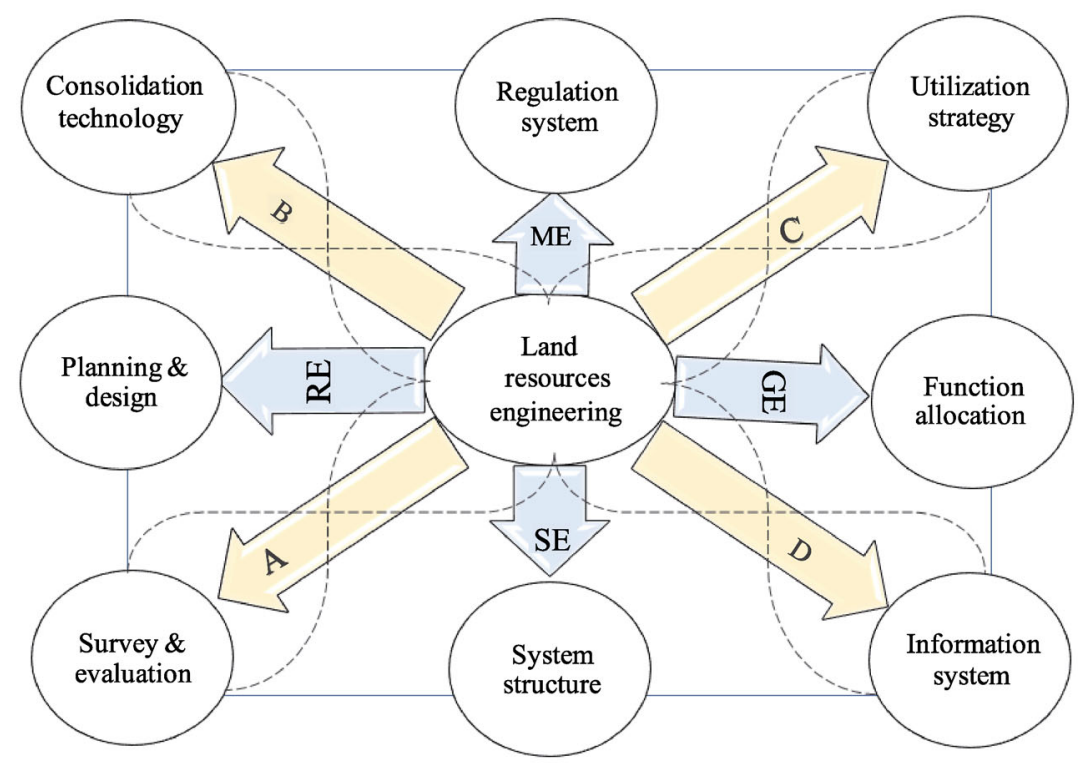

Figure 1 Innovative research system for land resources engineering

1) Basic theory: RE-resource engineering, SE-systems engineering, GE-geographical engineering, ME- management engineering

2) System content: A-land resource survey and evaluation, B-land resource improvement technology, C-land resources use management, D-land resources information system

\subsection{Innovative rural geography research methodologies}

New research methods and techniques have been created concerning rural geography transects (Liu et al., 2012; Lu et al., 2013), agricultural land configuration engineering (Han et al., 2012), rural regional system diagnostics (Liu et al., 2011c; Li et al., 2014), field location observational research (Li et al., 2013b; Liu et al., 2015b), and new ways have been found to integrate research in rural geography theories, methods and techniques in the course of empirical research. Particularly in research on the development of high-quality farmland, Liu Yansui has overseen the advancement of entity theoretical innovation, with soil components, water and soil configuration, and farmland landscape forming a structural chain, ${ }^{1}$ in which he has proposed a systematic hierarchical system for rural geography, from farm landscapes, to agricultural systems, rural systems and urban-rural systems; constructs a mi-

\footnotetext{
${ }^{1}$ Liu Yansui, "Chinese Land Integrated Research and Land Resources Engineering” (keynote speech at the Annual Conference of the China Society of Natural Resources in Zhengzhou, November, 2014).
} 
croscopic rural geography system consisting of microsomes, microstructures and micromorphology, and, on the basis of the microscopic system and macroscopic system with a hierarchical structure consisting of farmland, agriculture, villages, and urban and rural areas; and deconstructs the logical pathways and mechanisms of geographical system element penetration, structural links and functional coupling (Figure 2). At the micro level of the water-soil relationship, construction of the water and soil structure is the key to achieving the systems engineering of soil creation, soil configuration, soil improvement and fertilizer coupling. At the meso level of the human-land relationship, land use is the key to achieving comprehensive optimization of the farmland landscape and agricultural system. At the macro level of the urban-rural relationship, the regional urban-rural system is the key to exploring rural system renewal and urban-rural equalization, with the focus on system transformation and functional upgrading.
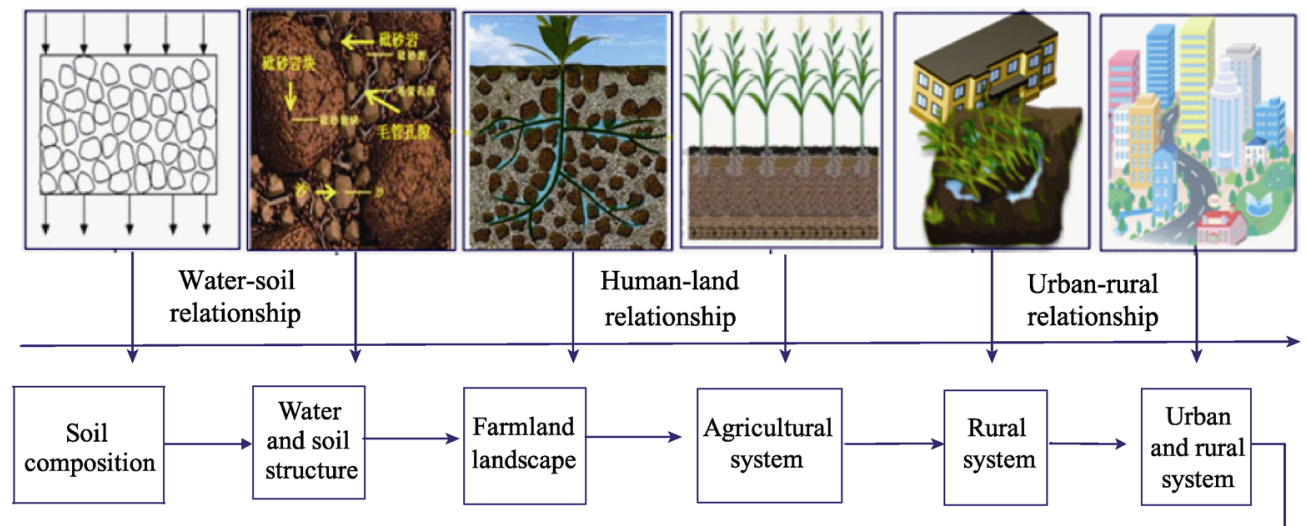

\section{Agricultural} modernization
Rural

modernization
New-type

urbanization

Figure 2 Rural geography project hierarchy system and coupling mechanisms

\section{Main research progress and achievements in Chinese rural geography in the past decade}

During the past decade, rural geography research has concentrated on integrating practical requirements with theoretical innovations, constantly explored integrated approaches to decision making and management innovation to meet national strategic needs, and made significant progress and innovative achievements in research on major regional geographical issues and the areas of technological innovation and consulting and decision making.

(1) Output of high-quality works

During the past decade, a series of influential academic works have been published, which have greatly promoted development of the disciplines of agricultural geography and rural development. Prof. Liu Yansui has edited four published volumes of the "Modern Agricultural and Rural Geography Series: "Geographical Theories on New Countryside Development", "Chinese Rural Regional Economic Theories", "Chinese Rural Transformation and Development and Land Use" and "Chinese Rural Community Space Theory". Other representative publications include "Chinese Rural Development Research Report-Rural 
Hollowing and Remedial Strategies", "Farmer Geographical Theories", "Chinese Agricultural Modernization and Farmers", "Rural Settlement Development and Evolution-Research on Rural Settlement Development in Loess Hilly and Gully Areas of Gansu" and "Sustainable Land Use in China." Breakthrough progress has been made in terms of the production of academic papers. A search of Acta Geographica Sinica for the period 2005-2016 reveals that there were 53 papers published with the word "rural" in their titles, which is more than three times as many as those published during the period 1950 to 2004. A number of influential papers have also been published in international publications, including Journal of Rural Studies, Applied Geography and Land Use Policy. In the Elsevier 2015 list of Most Cited Chinese Researchers in the field of social sciences, rural geographers Liu Yansui and Long Hualou were ranked third and fifth, respectively.

(2) Research incentives and talent programs

During the past decade, researchers have concentrated on applying their scientific research results and personnel training, and remarkable breakthroughs have been made in research incentives and talent programs. Prof. Liu Yansui won the Shaanxi Science and Technology Progress Award in 2005 for his paper on "Land resources development and regional coordinated development", the Hainan Science and Technology Award in 2009 for "Research on Hainan land use system assessments and decision optimization technology", the National Land Resources Science and Technology Award in 2013 for "Research on comprehensive improvement and optimal allocation of Chinese rural waste and unused land", and the Shaanxi Science and Technology Award in 2012 and 2014 for his involvement in the papers "Core technology and demonstration projects of soil formation from sedimentary rock and sand in the Mu Us Sandy Land" and "Research on the application of sand fixation technology to create fields in the Mu Us Sandy Land and its role in ecological improvement." Meanwhile, Yang Zisheng came second in the Yunnan Science and Technology Progress Award in 2009 for his paper "Eco-friendly land use research in mountainous areas of China: A case study of Yunnan Province." A group of outstanding young professionals trained in this field have received the National Geographic Science and Technology Award for Young Geographers, including Drs. Liu Yansui (fifth year), Zhang Xiaolin (sixth year), Long Hualou (ninth year) and Qiao Jiajun (tenth year). In 2013, Liu Yansui also received the title of Changjiang Distinguished Professor from the Ministry of Education, making him the first scholar in the field of rural geography and land-use management to receive such a distinction.

(3) Consultation and decision making on major national issues

In recent years, research focuses on the key battlefield of the national economy, served national and local economic and social development, and made important contributions to national decision making in the areas of new countryside development, new-type urbanization, targeted poverty alleviation and reduction policies, and integration of urban-rural development. Based on in-depth grassroots investigations and research, the CRARD team has completed 15 major advisory reports, which have received official comments from national leaders in the field. On August 30, 2013, Liu Yansui reported his research results on the topic "New rural urbanization should cure rural malaise" to Premier Li Keqiang, and his main recommendations were included in the 2014 Report on the Work of the Government. On August 26, 2015, CAS oversaw completion of "A Third-Party Assessment of Major 
Policies for Targeted Poverty Alleviation", which was reported to Premier Li Keqiang at an executive meeting of the State Council, and the issues raised by the report and its suggestions received the attention and affirmation of the leaders of the State Council. On April 14, 2016, Liu Yansui delivered a special report to Vice Premier Wang Yang entitled "Plan for A Third-Party Assessment of the Results of China's Targeted Poverty Alleviation.”

(4) Participation in formulating major plans

In recent years, in addition to their commitments to relevant research projects, scholars from this professional field have enthusiastically overseen or participated in important State-approved planning. For example, Liu Yansui and Long Hualou were responsible for agricultural science and technology innovation and development planning in the "Agriculture and Food Science and Technology Development Plan (2009-2020)", which involved 14 ministries and commissions, while Chen Yufu oversaw completion of the "Hainan Provincial Land Use Plan (2009)". Liu Yansui has also provided reports that form the basis for formulating major national plans and policies, including the "Planning and Design of the Centrally Supported Major Project for Gully Reclamation and Land Improvement in Yan'an, Shaanxi” in 2013, "Research on Rural Land System Reform in China" in 2014, "Third-Party Assessment of the Implementation of Major Policies and Measures of the State Council on Targeted Poverty Alleviation and Reduction" in 2015, and "A Third-Party Assessment Report of the Results of China's Targeted Poverty Alleviation Work” in 2016.

(5) Applying for national intellectual property rights protection

In response to the prevalence of "rural malaise" in China's rural areas, the strong points and technical methods from geography, information science, land engineering and other disciplines have been drawn together, based on the principles of being comprehensive, regional and practical, and new research methods have been created in rural geography and breakthroughs made in key technologies, for which applications have been made for national invention patents and software copyrights. For example, Liu Yansui and others have applied for seven patents, including "a type of rural waste homestead automatic information extraction method from remote sensing images" and "a type of detection method for urban-rural construction agglomeration", and they have received four software copyrights for "urban-rural integrated information management and planning decision" and "rural multi-functional assessment and performance evaluation support system" software.

\section{Development and prospects of rural geography in relation to major strategic needs}

As industrialization, urbanization and globalization continue apace, rural China is suffering from "rural malaise" (Liu, 2013), characterized by rapid de-agriculturalization of agricultural factors of production, overly quick weakening of farmers, constant wastage of rural construction land and serious polluting of rural water and soil environments. Particularly under the joint action of changes to rural factors of production and external regulation (Long et al., 2016), rural development problems, which have population and land at their core, are increasingly prominent. Since the 18th National Congress of the CPC, the central government has repeatedly and clearly proposed a series of major strategic measures aimed at promoting rural development, including integrating urban and rural development, promoting 
a new type of urbanization, developing beautiful villages and towns, and modernizing agriculture. In response to current major national strategic requirements and the need to resolve practical difficulties that have arisen in the course of urban-rural transformation and development, contemporary Chinese rural geography is involved in a number of new tasks, new missions and new topics. Future innovations and developments in rural geography disciplines should focus on the following aspects (Figure 3).

\begin{tabular}{|c|c|c|c|c|}
\hline \multicolumn{5}{|c|}{ International cooperation and exchange of rural geography research } \\
\hline - Regional cooper & tion platform & - Professional probl & - Glo & issues \\
\hline \begin{tabular}{|l|} 
Rural territorial \\
structure and function \\
- Elements \\
organization \\
and structure \\
evolution \\
- Function \\
identification and \\
development \\
orientation \\
- Territorial type \\
and allocation
\end{tabular} & $\begin{array}{l}\text { Urban-rural spatial } \\
\text { restructuring } \\
\text { - Spatial } \\
\text { organization } \\
\text { structure } \\
\text { - Restructuring } \\
\text { model and } \\
\text { approach } \\
\text { - Planning theory, } \\
\text { method and } \\
\text { technology }\end{array}$ & $\begin{array}{l}\text { Consolidation and } \\
\text { allocation engineering } \\
\text { - Land consolidation } \\
\text { engineering } \\
\text { - Environmental } \\
\text { governance } \\
\text { engineering } \\
\text { - Resources allocation } \\
\text { engineering } \\
\text { - Agricultural } \\
\text { double-excellent } \\
\text { engineering }\end{array}$ & $\begin{array}{l}\text { Theory and model of } \\
\text { rural governance } \\
\text { - Fundamental theory } \\
\text { innovation } \\
\text { - Coordinated pattern } \\
\text { and driving force } \\
\text { - Rural territorial type } \\
\text { and model } \\
\text { - Institution of } \\
\text { urbanization } \\
\text { - Rural poverty } \\
\text { alleviation }\end{array}$ & $\begin{array}{l}\text { Property rights and } \\
\text { mechanism innovation } \\
\text { - Land system and } \\
\text { assets capitalization } \\
\text { - Agricultural security } \\
\text { and marketization } \\
\text { - Urban-rural } \\
\text { equalized } \\
\text { development } \\
\text { - Regional and rural } \\
\text { sustainable } \\
\text { mechanism }\end{array}$ \\
\hline
\end{tabular}

Scientific issues and targets

Figure 3 Roadmap of rural geography research in China

(1) Rural regional structures and function values

Future rural geography studies need to focus on rural regional structures and function values and should strengthen system element organization, structure evolution, function identification and the differentiation and mechanisms of regional types; scientifically study and determine the functions of rural areas and their values; and highlight the combined values of the ecologies, economies, societies and cultures of Chinese rural regional systems in the course of social transformation. Following the law of regional differentiation, it is necessary to explore the formation mechanism of rural regional function differentiations and its evolutionary and dynamic mechanisms; to clarify the regional development position, resource allocation model and industrial development orientation of every functional zone; and to provide scientific bases for implementing national strategies, including the development of beautiful villages and towns, the overall revitalization of rural areas and the optimization of the social and economic spatial layout of rural areas.

(2) Urban-rural layout and spatial reconstruction

In response to the "urban malaise" caused by the excessive accumulation of production factors, and prominent rural problems, such as land resource wastage, lack of infrastructure, inefficient investment from public resources and disorderly rural development spaces caused by changes in rural population and land resources in the course of social transformation, urban-rural regional system should be taken as the starting point for exploring models and paths of urban-rural spatial organization, structure optimization and function restructuring models and paths for particular regions and development stages, and for studying spatial structures and patterns of hollowing village improvement, central village development and 
urban-rural integration, in accordance with the requirements of the national new urbanization strategy on spatial optimization of cities, towns and villages. Based on systematic analysis and study of urban-rural development factors, functions, mechanisms and models, and based on differences in regional types and development stages, new theories, methods and techniques are needed for urban-rural planning systems, in order to deal with the problems of urban and rural malaise, and to effectively promote the national strategies of new urbanization and urban-rural development integration.

(3) Soil and water resources improvement and allocation projects

Considering resource depletion, environmental pollution and eco-environmental deterioration caused by de-agriculturalization of rural factors of production in the course of rapid urbanization, through scientific and technological innovation in the areas of land resources engineering and land-related interdisciplinary research, it is necessary to discuss ways of dealing with inherent resource and environmental constraints; to promote projects aimed at achieving land improvement, environmental improvement, efficient resource allocation, and safe and quality agriculture based on local conditions; to strengthen regional water and land resource improvement and allocation; improve the health of, and organisms in, soil; to strengthen the foundations of modern agriculture; to enhance town and village construction capabilities; and effectively protect the livelihoods and interests of the people.

(4) Major theories and models of rural governance

In response to the national strategies of building beautiful villages, it is necessary to explore a framework for deepening rural governance research; scientifically assess the development potential and support capabilities of rural areas; analyse in-depth the pattern and dynamic mechanisms for the coupling between rural production, rural life and the environment; systematically develop basic theories and regional types of rural governance, rural poverty alleviation and development; explore new models of coordinated rural population, land, industry and ecology coupling based on local conditions; create new institutional mechanisms to modernize rural governance systems and capabilities; and provide consultations for decision making on national strategies, including building beautiful rural areas and developing new urbanization.

(5) Mechanisms for reforming and innovating the property rights systems

With practical issues in mind, such as the subjects of rural land property rights not being clear and having incomplete powers, which means it is difficult to achieve scale management of arable land, it is difficult to exchange empty homesteads and there is poor efficiency in allocating land resources, it is necessary to strengthen relevant research in areas centred on reform of the land property right system, such as rural land resource capitalization, the operating stock system and market-based allocation. It is also necessary to establish sound rural property value and income evaluation mechanisms, construct mechanisms and platforms to drive rural endogenous development and improve long-term mechanisms for external assistance, and provide policy support in order to promote the orderly flow and optimal allocation of urban and rural factors of production, achieve urban and rural equalization, stabilize agricultural production, ensure food security, and promote new urbanization and agricultural modernization.

(6) Promoting international cooperation and exchanges

Against the backdrop of globalization, the Chinese rural geography should foster a global 
research outlook; enthusiastically carry out international cooperation and cross-disciplinary collaborative research; recommend the establishment of an international association of land and rural development; build a global collaboration platform for research on rural economic and social development, project improvements and other relevant fields, and use it to discuss solutions to hunger, poverty, rural environmental degradation, disasters and other problems; promote mutual learning between countries on practical rural development, including agricultural development policies, rural land use, resource allocation models and reconstruction paths; strengthen research on regional cooperation between Asia, Africa and Latin America on popular issues such as impoverishment; and explore solutions and relevant coordinated mechanisms concerning global problems, including food security, rural environmental management, rural poverty and the effect of global climate change on sustainable rural development.

\section{Conclusions and discussion}

For nearly a decade, the Chinese studies on agricultural and rural geography are facing three main scientific issues in the areas of major national policy development, output of results and decision-making support: First, solving the regional spaces of urban and rural development; that is, the organizational and structural optimization of space, and analysing changes in spatial processes by looking at the urban-rural pattern of rural development and its optimal allocation. Second, rural value and functions, which involve exploring rural spatial organization, factor allocation efficiency, production development capabilities and other system problems, while focusing on the new pattern of town and village development. Third, scientific and technical innovations, including scientific early warnings, scientific forecasting and scientific decision making, to promote more in-depth research in globalized rural development, world poverty reduction and total factor labor production.

In terms of future international cooperative research, the China Urban-Rural Development Think Tank Alliance (CURTA) established in 2015 will serve as a platform to promote global agricultural and rural development cooperation; support global rural systematic and scientific decision making; highlight the spatial, interdisciplinary and regional features of geography; and systematically carry out analysis of big data and rural factor agglomeration under different flows (such as trade flows, population flows and information flows) and optimize decisions.

For nearly a decade, the Chinese urban-rural transformation and rural development research has concentrated on solving practical problems encountered in the course of urban and rural development in China, and used relevant theories and innovations in project technologies to support and serve scientific decision making in national urban and rural development and innovation in relevant rural systems. At the same time, the results of these studies and their paradigms have served as references for the future development of international agricultural and rural geography. Under economic globalization and future global planning guidance, the frontiers of international studies on agricultural and rural geography need to highlight four aspects of being strategic, systematic, scientific and security-oriented:

(1) Strategic: With the goal of global sustainable development in mind, it is necessary to promote strategic cooperation in modern agricultural and rural development between coun- 
tries and regions and work together to achieve a beautiful future of global harmony, health and security;

(2) Systematic: In order to solve practical problems including land degradation and environmental pollution, it is necessary to create new land resources engineering and environmental engineering technologies, strengthen cooperation and coupling between natural ecosystems and human social systems, and promote integrated applied research on rural geographic factor organization, structural optimization and system function upgrading;

(3) Scientific: It is necessary to strengthen scientific methods and systems in research on regional agricultural and rural development, abide by the element-structure-function-system coupling principle, scientifically explore the regional spatial patterns, evolutionary laws and dynamic mechanisms of urban and rural development;

(4) Security-oriented: Rural security issues generally include hunger, poverty, environmental problems and disasters, and given that, against the backdrop of global integration and economic restructuring, security problems usually have complex causes, are diverse and have far-reaching effects, it is necessary to explore the different types and various drivers of rural safety strategies for different development stages.

Moreover, international research on rural geography needs to shift from the previous focus on regional and local studies to a focus on problem areas and to global studies concerning food security, rural environmental changes and rural poverty.

\section{References}

Bai Xuemei, Shi Peijun, Liu Yansui, 2014. Realizing China's urban dream. Nature, 509: 158-160.

Brown M E, Funk C C, 2008. Food security under climate change. Science, 319(5863): 580-581.

Chen Xiaohua, Zhang Xiaolin, Ma Yuanjun, 2008. China's rural spatial transition in the period of rapid urbanization. Journal of Nanjing Normal University (Natural Science Edition), 31(1): 125-129. (in Chinese)

Chen Ruishan, Ye Chao, Cai Yunlong et al., 2014. The impact of rural out-migration on land use transition in China: Past, present and trend. Land Use Policy, 40: 101-110.

Chen Yufu, Sun Hu, Liu Yansui, 2010. Reconstruction models of hollowed villages in key agricultural regions of China. Acta Geographica Sinica, 65(6): 727-735. (in Chinese)

Fang Yangang, Liu Jisheng, 2014. The modification of North China quadrangles in response to rural social and economic changes in agricultural villages: 1970-2010s. Land Use Policy, 39: 266-280.

Huang Jikun, Yang Jun, Chou Guanghuan, 2012. Thinking on national food security strategies and policies. Issues in Agricultural Economy, 3: 4-8. (in Chinese)

Li Erling, Pang Anchao, Zhu Jiguang, 2012. Analysis of the evolution path and mechanism of China's agricultural agglomeration and geographic pattern. Geographical Research, 31(5): 885-898. (in Chinese)

Li Yuheng, Chen Cong, Wang Yanfei et al., 2014. Urban-rural transformation and farmland conversion in China: The application of the environmental Kuznets Curve. Journal of Rural Studies, 33: 311-317.

Li Yuheng, Li Yurui, Hans Westlund et al., 2015a. Urban-rural transformation in relation to cultivated land conversion in China: Implications for optimizing land use and balanced regional development. Land Use Policy, 47: 218-224.

Li Yuheng, Zhang Zhenghe, Westlund Hans et al., 2015b. Rural household income in transitional China: Spatio-temporal disparity and its interpretation. China: An International Journal, 13(2): 151-168.

Li Yurui, Cao Zhi, Zheng Xiaoyu et al., 2016. Regional and sustainable approach for target-poverty alleviation and development of China. Bulletin of Chinese Academy of Sciences, 31(3): 279-288. (in Chinese)

Li Yurui, Liu Yansui, Long Hualou et al., 2013a. Village transformation development, resources and environment effects and their optimal regulation in the metropolitan suburbs: The case of Beicun in Shunyi District, Beijing. 
Acta Geographica Sinica, 68(6): 825-838. (in Chinese)

Li Yurui, Liu Yansui, Long Hualou et al., 2013b. Local responses to macro development policies and their effects on rural system in mountainous regions: The case of Shuanghe Village in Sichuan Province. Journal of Mountain Science, 10(4): 588-608.

Li Yurui, Liu Yansui, Long Hualou et al., 2014. Community-based rural residential land consolidation and allocation can help to revitalize hollowed villages in traditional agricultural areas of China: Evidence from Dancheng County, Henan Province. Land Use Policy, 39: 188-198.

Li Yurui, Long Hualou, Liu Yansui, 2015. Spatio-temporal pattern of China's rural development: A rurality index perspective. Journal of Rural Studies, 38: 12-26.

Liu Shaoquan, Xie Fangting, Zhang Haiqin et al., 2014. Influences on rural migrant workers' selection of employment location in the mountainous and upland areas of Sichuan, China. Journal of Rural Studies, 33(1): $71-81$.

Liu Yansui, 2007. Rural transformation development and new countryside construction in eastern coastal area of China. Acta Geographica Sinica, 62(6): 563-570. (in Chinese)

Liu Yansui, 2011. Scientifically promoting the strategy of reclamation and readjustment of rural land in China. China Land Science, 25(4): 3-8. (in Chinese)

Liu Yansui, 2013. New urbanization should cure rural disease. People's Daily, 2013-09-10. (in Chinese)

Liu Yansui, 2015. Integrated land research and land resources engineering. Resources Science, 37(1): 1-8.

Liu Yansui, Chen Cong, Li Yurui, 2015a. Differentiation regularity of urban-rural equalized development at prefecture-level city in China. Journal of Geographical Sciences, 25(9): 1075-1088.

Liu Yansui, Fang Fang, Li Yuheng, 2014. Key issues of land use in China and implications for policy making. Land Use Policy, 40: 6-12.

Liu Yansui, Guo Yanjun, Li Yurui et al., 2015b. GIS-based effect assessment of soil erosion before and after gully land consolidation: A case study of Wangjiagou Project Region, Loess Plateau. Chinese Geographical Science, 25(2): 137-146.

Liu Yansui, Li Yuheng. China's land creation project stands firm. Nature, 2014, (511): 410.

Liu Yansui, Liu Yu, Chen Yufu et al., 2010. The process and driving forces of rural hollowing in China under rapid urbanization. Journal of Geographical Sciences, 20(6): 876-888.

Liu Yansui, Liu Yu, Chen Yufu, 2011a. Territorial multi-functionality evaluation and decision-making mechanism at county scale in China. Acta Geographica Sinica, 66(10): 1379-1389. (in Chinese)

Liu Yansui, Long Hualou, Chen Yufu et al., 2011b. China Rural Development Research Report: Rural Hollowing and Its Remediation Strategy. Beijing: Science Press. (in Chinese)

Liu Yansui, Long Hualou, Zhang Xiaolin et al., 2011c. Research progress and prospect in the disciplines of agricultural geography and rural development in China. Progress in Geography, 30(12): 1498-1505. (in Chinese)

Liu Yansui, Lu Dadao, 2003. The basic trends and regional effects of agricultural structure adjustment in China. Acta Geographica Sinica, 58(3): 381-389. (in Chinese)

Liu Yansui, Lu Shasha, Chen Yufu, 2013a. Spatio-temporal change of urban-rural equalized development patterns in China and its driving factors. Journal of Rural Studies, 32: 320-330.

Liu Yansui, Yang Ren, 2015. The spatial pattern measure of urban-rural development transformation in the Bohai Rim region in China. Acta Geographica Sinica, 70(2): 248-256. (in Chinese)

Liu Yansui, Yang Ren, Li Yuheng, 2013b. Potential of land consolidation of hollowed villages under different urbanization scenarios in China. Journal of Geographical Sciences, 23(3): 503-512.

Liu Yansui, Zhou Yang, Liu Jilai, 2016. Regional differentiation characteristics of rural poverty and targeted poverty alleviation strategy in China. Bulletin of Chinese Academy of Sciences, 31(3): 269-278. (in Chinese)

Lobell D B, Burke M B, Tebaldi C et al., 2008. Prioritizing climate change adaptation needs for food security in 2030. Science, 319(5863): 607-610.

Long Hualou, 2014. Land consolidation: An indispensable way of spatial restructuring in rural China. Journal of Geographical Sciences, 24(2): 211-225.

Long Hualou, Li Yurui, Liu Yansui, 2009a. Analysis of evolutive characteristics and their driving mechanism of 
hollowing villages in China. Acta Geographica Sinica, 64(10): 1203-1213. (in Chinese)

Long Hualou, Li Yurui, Liu Yansui et al., 2012. Accelerated restructuring in rural China fueled by 'increasing vs. decreasing balance' land-use policy for dealing with hollowed villages. Land Use Policy, 29(1): 11-22.

Long Hualou, Liu Yansui, Li Xiubin et al., 2010. Building new countryside in China: A geographical perspective. Land Use Policy, 27(2): 457-470.

Long Hualou, Tu Shuangshuang, Ge Dazhuan et al., 2016. The allocation and management of critical resources in rural China under restructuring: Problems and prospects. Journal of Rural Studies, 46. doi: 10.1016/j.jrurstud.2016.03.011.

Long Hualou, Zou Jian, Liu Yansui, 2009b. Differentiation of rural development driven by industrialization and urbanization in eastern coastal China. Habitat International, 33(4): 454-462.

Long Hualou, Zou Jian, Pykett J et al., 2011. Analysis of rural transformation development in China since the turn of the new millennium. Applied Geography, 31(3): 1094-1105.

Qiao Jiajun, Lee Jay, Ye Xinyue, 2016. Spatiotemporal evolution of specialized villages and rural development: A case study of Henan province, China. Annals of the Association of American Geographers, 106(1): 57-75.

Schmidhuber J, Tubiello F N, 2007. Global food security under climate change. Proceedings of the National Academy of Sciences, 104(50): 19703-19708.

Wang Jieyong, Liu Yansui, 2009. The changes of grain output center of gravity and its driving forces in China since 1990. Resources Science, 31(7): 1188-1194. (in Chinese)

Wang Jieyong, Liu Yansui, Chen Yufu, 2012. Empirical research on household willingness and its caused factors for land consolidation of hollowing village in Huang-Huai-Hai traditional agricultural area. Scientia Geographica Sinica, 32(12): 1452-1458. (in Chinese)

Wang Jieyong, Liu Yansui, Chen Yangfen, 2013. Empirical analysis on influencing factors of the hollowing village degree-based on the survey data of sample villages in Shandong Province. Journal of Natural Resources, 28(1): 10-18. (in Chinese)

Woods M, 2005. Rural Geography: Processes, Responses and Experiences in Rural Restructuring. London: Sage.

Yang Ren, Liu Yansui, Long Hualou et al., 2015. Research progress and prospect of rural transformation and reconstruction in China: Paradigms and main content. Progress in Geography, 34(8): 1119-1130. (in Chinese)

Yang Yuanyuan, Liu Yansui, Zhang Ziwen, 2016. Study on policy innovation and suggestions of targeted poverty alleviation based on typical investigation. Bulletin of Chinese Academy of Sciences, 31(3): 337-345. (in Chinese)

Yun Wenju, Yu Zhengrong, 2011. Ecological landscaping strategy of rural land consolidation in China. Transactions of the Chinese Society of Agricultural Engineering, 27(4): 1-6. (in Chinese)

Zhang Yifeng, Jia Dameng, Tan Jie et al., 2009. The spatial structure of valley economy development in the mountainous areas of Beijing. Acta Geographica Sinica, 64(10):1231-1242. (in Chinese)

Zhou Yang, Liu Yansui, Wu Wenxiang et al., 2015. Effects of rural-urban development transformation on energy consumption and $\mathrm{CO}_{2}$ emissions: A regional analysis in China. Renewable and Sustainable Energy Reviews, 52 : $863-875$. 